\title{
Changes in radiological protection and quality control in Spanish dental installations: 1996-2003
}

\author{
Miguel Alcaraz-Baños ${ }^{1}$, María del Carmen Parra-Pérez ${ }^{2}$, David Armero-Barranco ${ }^{3}$, Francisco Velasco- \\ Hidalgo ${ }^{1}$, Esteban Velasco-Hidalgo ${ }^{1}$
}

${ }^{1}$ Área de Radiología y Medicina Física. Facultad de Medicina/Odontología, Universidad de Murcia. 30100-Campus de Espinardo. Murcia

2 Área de Estomatología, Facultad de Medicina/Odontología, Universidad de Murcia

${ }^{3}$ Departamento de Enfermería. Escuela Universitaria de Enfermería, Universidad de Murcia. 30100-Campus de Espinardo. Murcia

Correspondence:

Área de Radiología y Medicina Física.

Facultad de Medicina/Odontología

Universidad de Murcia

30100- Campus de Espinardo

mab@um.es

\begin{abstract}
Alcaraz-Baños M, Parra-Pérez MC, Armero-Barranco D, Velasco-Hidalgo F, Velasco-Hidalgo E. Changes in radiological protection and quality control in Spanish dental installations: 1996-2003. Med Oral Patol Oral Cir Bucal. 2009 Oct 1;14 (10):e499-505.

http://www.medicinaoral.com/medoralfree01/v14i10/medoralv14i10p499.pdf
\end{abstract}

Received: 07/07/2008

Accepted: 20/05/2009

\begin{abstract}
Introduction: The European Union has established specific directives concerning radiological protection which are obligatory for member States. In addition, all Spanish dental clinics with radiological equipment are required to have an annual quality control check. Objective: To analyze the effect of new European legislation on dental radiological practice in Spain and to determine whether it has resulted in lower doses being administered to patients. Material and Methods: A total of 10,171 official radiological quality control reports on Spanish dental clinics, covering 16 autonomous regions, were studied following the passing of Royal Decree 2071/1995 on quality criteria in radiodiagnostic installations. The reports, compiled by U.T.P.R Asigma S.A., a company authorised by the Nuclear Safety Council, cover the years 1996 to 2003, which has enabled us to monitor the evolution of radiological procedures in dental clinics over a seven year period. Results: According to the reports for $2003,77.3 \%$ of clinics complied with EU requirements, using equipment of $70 \mathrm{kVp}, 8 \mathrm{~mA}, 1.5 \mathrm{~mm} \mathrm{Al}$ filters, with a collimator length of $20 \mathrm{~cm}$. However, non-compliance was detected in approximately a third $(30.8 \%)$ of the equipment inspected: alterations in the kilovoltage used, exposure time, performance of the tubing, dosage, linearity/intensity of current and acoustic-luminous signal $6.86 \%$. The mean skin dose reached $3.11 \mathrm{mGy}$ for patients who received an $\mathrm{x}$-ray of an upper molar, representing a decrease of $18 \%$ over the seven years studied. Conclusion: there has obviously been a general improvement in the parameters studied, but only $77.3 \%$ of the installations complied fully with official EU regulations concerning dental radiological protection.
\end{abstract}

Key words: Dental radiodiagnosis, quality control, radiography, intraoral radiology, radiation dose. 


\section{Introduction}

The European Union, following the directives of the International Commission of Radiological Protection under the auspices of EURATOM, has established as series of directives (1-3) concerning radiological protection which are mandatory in all member states until such laws are passed in individual countries. In the case of Spain, Royal Decree 2071/1995 (4) established that all dental clinics equipped with intraoral radiological equipment must be subject to annual quality control inspections.

Subsequently Royal Decree 1976/1999 (5) substituted the above law, introducing minor changes, among which were minimum quality criteria in radiodiagnosis which must fulfil a quality control programme.

At present the number of medical radiological examinations carried out annually in Spain is 25,058,622; that is, 62 per 1000 inhabitants, of which approximately 20.85 $\%(5,226,823)$ refer to dental examinations $(6,7)$. This annual figure of dental examinations (131/1000 inhabitants) is below the corresponding rate for most EU member states (7). For example, the number of dental clinics in the United Kingdom is 39/100,000 habitants, which, in 1994, performed 16 million dental radiological examinations per year (8), a figure which had risen by another two million examinations by 2001 (9).

As a result of the increasing number of dental radiological examinations in recent years, efforts are being made to reduce the radiation doses administered in the same $(8,10-14)$. The mandatory annual quality control inspections of clinics using radiological equipment established by Spanish Royal Decree 2071/1995 (1995) (4), provide data that permit an overall view of the situation of dental radiology in Spain and of the behaviour of dentists in this respect (15). Such knowledge of the safety of radiological equipment and the way in which it is used will help reduce the exposure risks to patients and workers exposed to ionising radiation (16-18).

\section{Objetives}

To determine the effect of recent EU legislation on Spanish radiological practice in dental clinics and any reduction in the dose administered to patients, establishing the parameters that affect such exposure, by reference to data for 1996 (prior to the introduction of the legislation) and the data available for the six years corresponding to 1998-2003.

\section{Material and Methods}

We examined 10,171 radiodiagnosis quality control reports covering the first seven years following the application of Royal Decree 2071/1995, which established quality criteria for dental clinics in Spain. The technical inspections were carried out by the Radiological Protection Unit of ASIGMA, S.A.L., a company authorised by the Spanish Nuclear Safety Council and covered all the installations that had to submit to such controls. Most clinics were private and belonged to 40 provinces within 16 Autonomous Communities of Spain. All the clinics had been authorised by the Nuclear Safety Council, which implies that they had already been inspected by a radiological protection unit.

The reports provided information on alterations observed in the functioning of intraoral radiological equipment, the variables analysed are those described in the Royal Decrees 2071/1995 (4) and 1976/1999 (5). The information was collected by three expert technicians of the company concerned and covered the make and model of the equipment, the kilovoltage and milliamperage at which it works and the filtration used. The quality control reports describe as an anomaly any variation measured during five consecutive exposures that exceeded $\pm 10 \%$ of the $\mathrm{kV}$ and the $\mathrm{mA}$ stated by the manufacturer. The reports also described anomalies in the behaviour, reproducibility and dosis linearity/intensity when these exceeded $\pm 10 \%$. Whether or not a trigger existed and, if so, its type, and any alterations in the acoustic-luminous signal (not audible or not visible).

Information on the conditions in which the film were developed and the type of development (manual, automatic, radiovisiography or self-developing) was also included in the reports, as was the temperature of the developing liquids and renewal frequency, development times, film type and whether the film was stored inside or outside the exploration room.

The mean radiation dose (in $\mathrm{mGy}$ ) reaching the patient's skin and exposure time (in seconds) were established for an X-ray of the second upper molar in the normal working conditions of each clinic. In the last two years of the study (2002-2003), the mean doses and exposure time for a second lower molar, and upper and lower incisor were also established using a semiconductor detector (PMX III, Spain) and occasionally, following the norm double control of recommended measure the dose was measured by thermoluminescence using a dosimeter (Conqueror Electronics Technology Co, China) supplied and read by the Centre for Energy, Environmental and Technological Research (CIEMAT Spanish) of the Ministry of Science and Technology. The reports did not consider backscatter in the numerical value of the dose, and neither have we in an attempt to reflect as closely as possible the information provided. Subsequently, a group comparison was made by analysis of variance, complemented by a contrast of the equality of means using least significant difference method, taking as statistically significant values of $p$ lower than $0.05(p<0.05)$. The quantitative variables were related by regression analysis and linear correlation. 


\section{Results}

The number of X-ray models used increased substantially during the seven years covered by the study, reaching 63 models from 23 different companies in 2003 , when $68.19 \%(1808 / 1233)$ of the clinics used the Trophy models, followed by Gendex-Philips (10.56\%; 1808/191) (Table 1).

a) Characteristics of intra oral radiology apparatus

The power of the X-ray machines used varied from 50 $\mathrm{kVp}$ to $70 \mathrm{kVp}$, the number meting the recommendation to use this higher voltage increasing over the years. In $1996-97,61.67 \%$ of the machines worked at $70 \mathrm{kVp}$, which had risen to $77.27 \%$ by 2003 ; that is an increase of $15.6 \%$ in seven years (Fig. 1).

Similarly, $80.7 \%(1808 / 1459)$ of the machines used 8 $\mathrm{mA}$ in 2003 , the value recommended by the EU, which is slightly lower $(5.01 \%)$ than the increase observed for the kilovoltage.

During the first inspection, which served as starting point for this study, the filtration added of the primary bundle varied from $0 \mathrm{~mm} \mathrm{Al}$ to $3.4 \mathrm{~mm}$ de $\mathrm{Al}$, the recommended value being $1.5 \mathrm{~mm}$ or more in apparatus working at up to $70 \mathrm{kVp}$. This first inspection showed that $98.97 \%(1370 / 1356)$ used $1.5 \mathrm{~mm} \mathrm{Al}$, while in $200369.19 \%(1805 / 1249)$ used $2.5 \mathrm{~mm}$ which is a far greater number than the $36.49 \%$ (1370/500) using this thickness in 1996-1997.

The results point to statistically significant $(p<0.05)$ differences in the doses administered by the different models, two makes (Castellini and Villa) emitting considerably more radiation than others.

Table 1. Relation of marks of devices of radiology intraoral determined in the study belonging to the seventh review (2003).

\begin{tabular}{|l|c|c|}
\hline \multicolumn{1}{|c|}{ MAKE } & NUMBER & $\begin{array}{c}\text { PERCENAGE } \\
\text { (\%) }\end{array}$ \\
\hline TROPHY & 1233 & 68.19 \\
\hline GENDEX-PHILIPS & 191 & 10.56 \\
\hline SATELEC & 132 & 7.30 \\
\hline TAKARA-BELMONT & 62 & 3.43 \\
\hline ARDET & 57 & 3.15 \\
\hline SIEMENS & 26 & 1.44 \\
\hline PLANMECA & 21 & 1.16 \\
\hline CASTELLINI & 18 & 1 \\
\hline VILLA & 18 & 1 \\
\hline CIAS & 11 & 0.61 \\
\hline SIRONA & 7 & 0.38 \\
\hline OTROS TOTAL & 1.808 & $100(\%)$ \\
\hline
\end{tabular}

$14.05 \%(1252 / 176)$ of installations inspected in the first year of the study used a fixed trigger installed outside the exploration room, although $84.66 \%(1252 / 1060)$ had the recommended cable of at least 2 metres. The number of installations using a cable length of less than $2 \mathrm{~m}$ fell during the six years of the study $(17.64 \%)$, while the number using external triggers rose $(82,12 \%)$.

$93 \%(1370 / 1274)$ of installations in 1996-97 had an acoustic-luminous signal working correctly, the rest either having no signal or a signal that was working incorrectly. In 2003 only $\mathrm{n}$ the last year, only $93 \%$ $(1370 / 1274)$ of signals worked incorrectly. This is an important statistic because a mal-functioning signal can provoke a significant increase $(\mathrm{p}<0.05)$ in the radiation dose reaching the patient.

The use of radiological equipment complying with EU recommendations $(70 \mathrm{kVp}, 2.5 \mathrm{~mm} \mathrm{Al}, 20 \mathrm{~cm}$ collimator) (19) significantly $(\mathrm{p}<0.05)$ reduces the radiation does emitted.

b) Anomalies found

In 1996-97, $9.92 \%(1370 / 136)$ installations inspected showed alterations in the $\mathrm{kVp}$ reached of more than $10 \%$. Almost $6.7 \%(1370 / 92)$ showed anomalies in the exposure times marked by the chronometer. As many as $9.4 \%(1370 / 129)$ showed deviations in X-ray tube performance (radiation dose per unit of time) in excess of $20 \%$. Other important anomalies were less frequent: deviations in the reproducibility of the dose $(0.68 \%$ : 1370/3); deviations in the reproducibility of the time ( $0.68 \%: 1370 / 3)$; or alterations in the dosis linearity/ intensity of current (3.94\%: 1370/54).

The results for 2001 show that $8.9 \%$ of the installations presented anomalies as regards the $\mathrm{kVp}$ described by the manufacturer, $14.2 \%$ as regards exposure time, $4.1 \%$ as regards X-ray tube performance and $3.3 \%$ as regards dosis linearity/intensity of current (Fig. 2). The number of faults same recurred in 2003, meaning that almost a third of the equipment revised still had serious malfunctions.

c) Development conditions.

During the first inspection (1996-1997), most clinics developed the film manually, $87.31 \%$ (1190/1139), while only $6.72 \%(1190 / 80)$ had automatic equipment. Digital systems were only present in $4.45 \%$ (1190/53) of installations.

In 2003 most continued to rely on manual development (74.97\%: 1790/1342), (4,81\%: 1790/87) used automatic equipment and there was a growing tendency to use radiovisiography: 19.3\% (1790/349).

The first inspection (1996-1997) found that there was no control of the liquids used for development in $99.31 \%$ $(1021 / 1014)$ of the clinics, while in the last inspection. (2003) 9373\% (1437/1347) still developed film at room temperature. In 1996-7, the liquids were renewed weekly in $65.62 \%(931 / 661)$ of cases, rising to $90.51 \%$ $(1434 / 12989$ in 2003. 


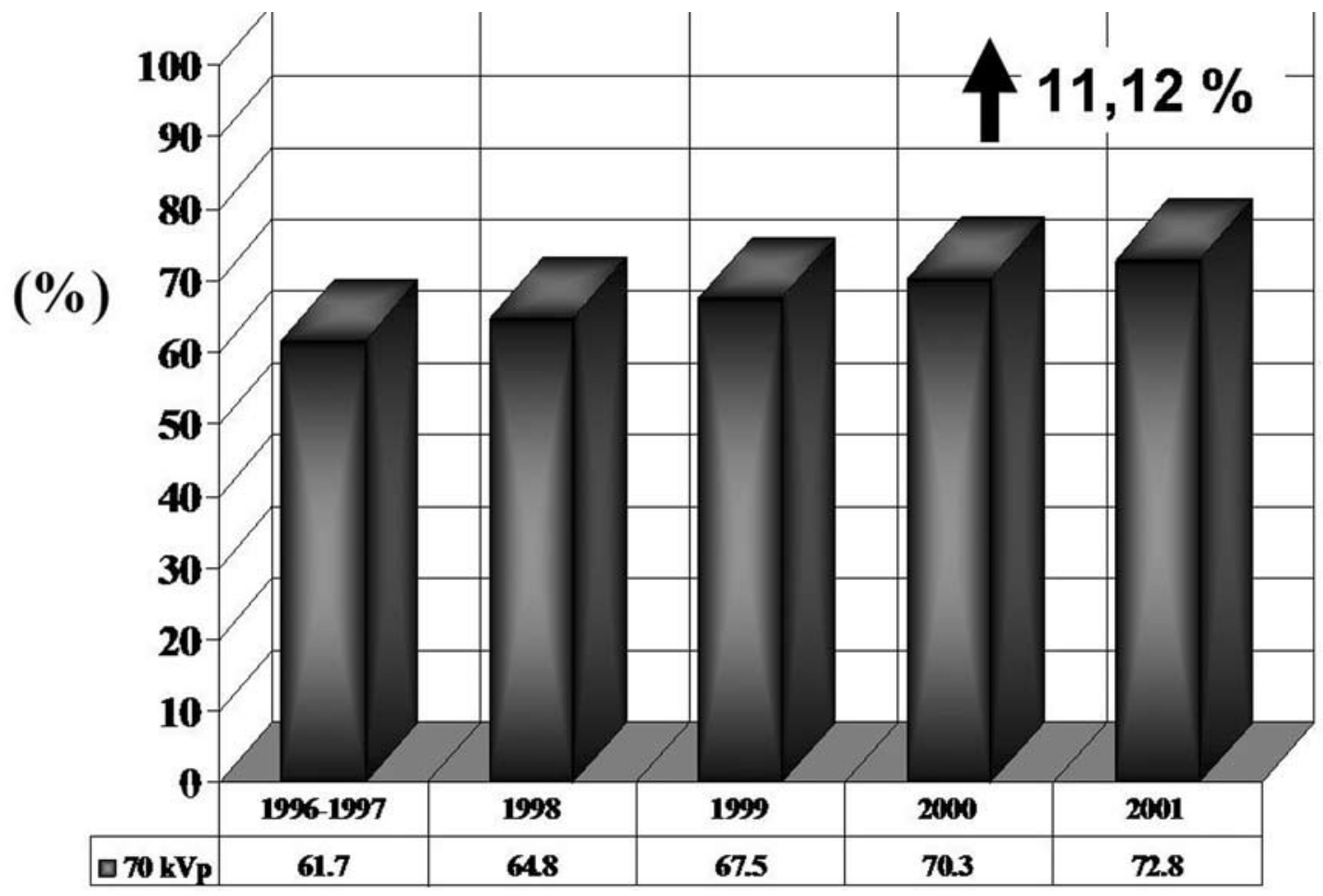

Evolution of number of radiological devices working at $70 \mathrm{kVp}$

years

Fig. 1. Evolution of number of radiological devices working at $70 \mathrm{kVp}$.

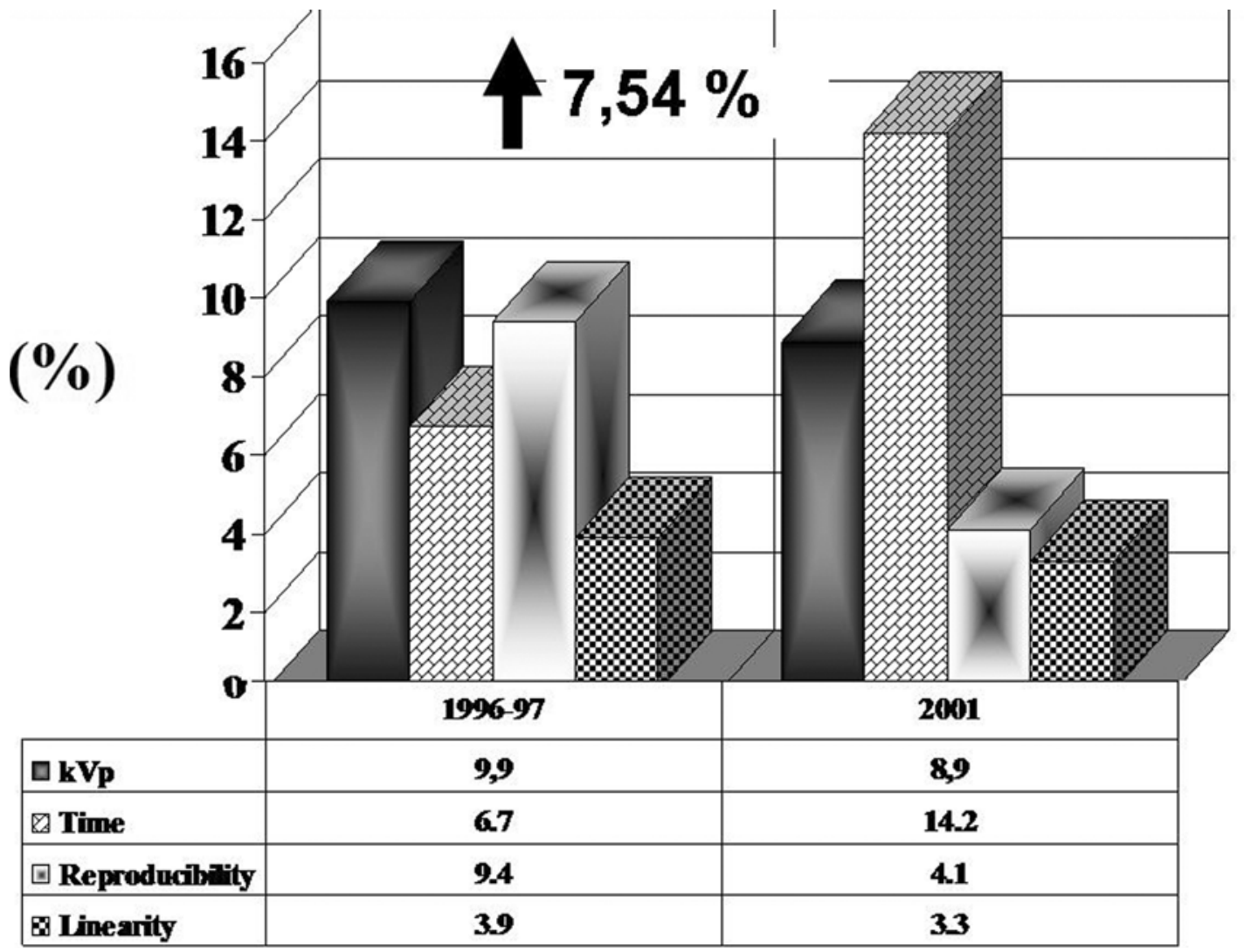

Fig. 2. Evolution of number of devices anomalies. 


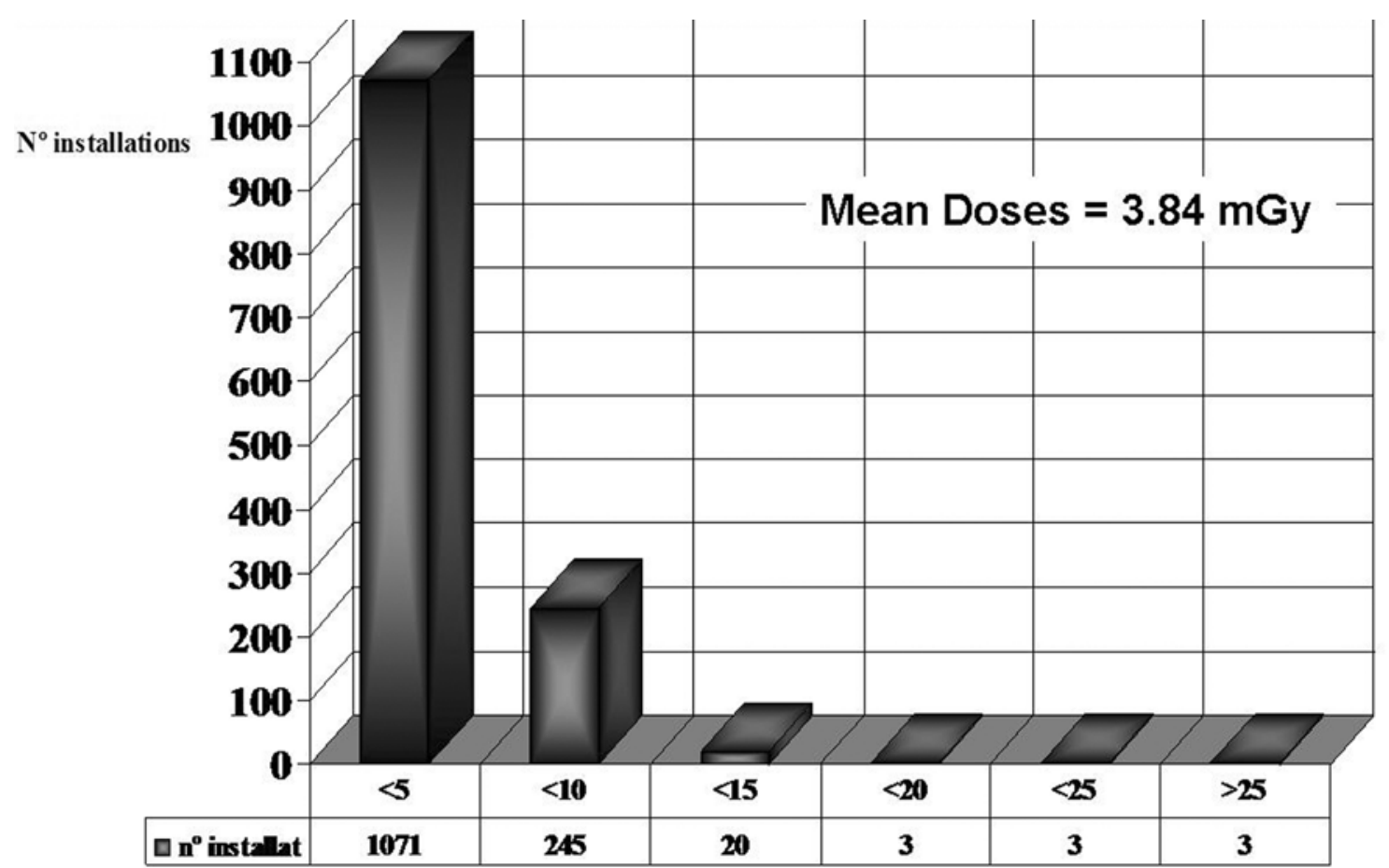

Fig. 3. Doses administered in dental clinics: 1996-97.

Of the installations studied in the first year studied (19961997), 72.58\% (1222/887) used Ultraspeed ${ }^{\circledR}$ (Kodak), with a D sensitivity rating. By 2003 , this number had grown to $82.3 \%$ (1441/1349).

The development or processing time was not controlled in $80.13 \%(1007 / 807)$ of installations in the first year, but was in $19.86 \%(1007 / 200)$. The corresponding figures for the last year were $71.18 \%(1423 / 1013)$ who controlled the time compared with $28.67 \%$ (1423/408) who did not.

In 1996-7, the radiological film was stored in the same room as X-rays were taken in $48.98 \%(1088 / 532)$ of cases, which had fallen to $6.38 \%(1441 / 92)$ by 2003 .

Statistically significant differences were found between the radiation dose administered and the time at which the developing liquids were changed. When this was done weekly or fortnightly, the significance rose significantly $(p<0,001)$ :the longer between changes, the greater the ionizing radiation dose used to obtain the radiological image.

Significant differences $(\mathrm{p}<0.05)$ were obtained between the radiation dose administered and the X-ray method used (manual, automatic or digital). The manual and automatic processing led to the same dose being administered, while the digital processing involved significantly higher doses: Manual $=$ Automatic $>$ Digital $(\mathrm{p}<0.05)$.

d) Mean radiation dose and exposure time.
The estimated dose for a second upper molar in the normal conditions used in each clinic was lower than $5 \mathrm{mGy}$ in $79.62 \%(1345 / 1071)$ of installations in 1996-97, the mean being $3.4 \mathrm{mGy}$. This means that $92 \%(1370 / 1260)$ were complying with the EU regulations of $7 \mathrm{mGy}$ maximum dose in force at that date (Figure 3).

In the corresponding inspection for 2003 , practically all clinics used less than $7 \mathrm{mGy}(97.22 \%$ : 1153/846) and $73.37 \%$ (1153/846) complying with the new EU recommendations to use doses lowers than $4 \mathrm{mGy}$ (19). The maximum values found were $15.5 \mathrm{mGy}$ and the mean $3.11 \mathrm{mGy}$. For the new registered exhibitions mean doses were: 2.20 for a lower molar, 2.16 for an upper incisor and 1.82 for a lower incisor.

The exposure times used to obtain radiographic images were 0.2 to 0.5 seconds, these times being very similar for the last two inspections (2002- 2003). 0.5 seconds was the most frequent exposure time foe an upper molar and 0.3 for a lower molar, and upper and lower incisor. Significant differences were observed between the radiation dose and type of film used or digital image obtained $(\mathrm{p}<0.001)$, the last technique needing a lower dose than either of the two other procedures (manual and automatic).

The establishment of quality control legislation led to a $18.5 \%$ reduction in the mean doses administered in the years examined. 


\section{Discussion}

According to the census of radiological installations carried out by UNSCEAR in $2000(6,7)$, there were 7327 dental installations in Spain, so that our study refers to 20.45 of the total.

The equipment used in Spain can be regarded as very similar to that used in the rest of the industrialised world in terms of $\mathrm{kVp}, \mathrm{mA}$ and filtration, since they are generally manufactured by the same multinational companies (20).

A slight improvement can be observed with respect to the values described by other authors, who noted extremes of $45 \mathrm{kVp}$ and $90 \mathrm{kVp}(21)$, which cannot only be put down to the years elapsing between the studies since this type of apparatus is still in operation.

Our findings reveal that $96.8 \%$ of dental clinics used intraoral equipment working at $60-70 \mathrm{kVp}$, which is considerable higher than the figure $(40 \%)$ for Denmark almost ten years ago. In 2003 , only $77.27 \%$ of dental installations used the $70 \mathrm{kVp}$ recommended by the $\mathrm{EU}$, although there was a positive trend in that $11.2 \%$ of professionals changed their old equipment during the six years of the study.

As regards the milliamperage, of the equipment, the values determined varied between 7 and $12 \mathrm{~mA}$, only $80.7 \%$ of the equipment inspected working at the $8 \mathrm{~mA}$ recommended by the EU. The figures increased by 5.01 5 during the seven years of the study, so that progress was slow but positive. Very few studies deal with this aspect in other countries. However, in Finland figures for 1988, which do not necessarily reflect the present situation, varied between 5 and $15 \mathrm{~mA}$.

Antiquated equipment is not the preserve of underdeveloped countries but also of more modernised ones. For example Australian studies have revealed that $25 \%$ of medical radiodiagnostic equipment may operate incorrectly, either though not complying with official recommendations or because the machinery involved is old and has technological limitations (22).

Despite everything, intraoral radiological apparatus tends to be manufactured by multinational companies which offer a specific type of apparatus, traditionally regarded as the most straightforward of medical radiological devices. However, after-sales maintenance seems to be poor and faults may persist. Almost a third of the equipment inspected in 2003 showed significant alterations in the physical characteristics $(\mathrm{kVp}$, exposure time, performance, linearity, acoustic signal), which represents an improvement over the first inspection (1996-7), when $38.84 \%$ showed faults. However, this does not avoid the fact that about a third of all equipment inspected each year showed some fault.

It is currently accepted that, when using dental radiological equipment, a constant potential of the $\mathrm{X}$-ray device (recommended $70 \mathrm{kVp}, 8 \mathrm{~mA}$ ), a skin- focus distance of $20 \mathrm{~cm}$, the correct filter of $1.5 \mathrm{~mm}$ $\mathrm{Al}$ contribute considerably to reducing the exposure of patients $(8,10,16)$. These parameters are reflected in the reports, which show that only $77.27 \%$ of installations inspected in the last year of the study complied with these official recommendations, although this is a $15.6 \%$ improvement over the initial situation. A study carried out by ZHANG and co-workers (23), showed that the use of a rectangular collimator, together with a cone distance of $20 \mathrm{~cm}$ and $2 \mathrm{~mm} \mathrm{Al}$ filter is sufficient to reduce the dose absorbed by the patient by $90 \%$.

Our finding show that the mean radiation dose for an upper molar in Spain was 3.84 for 1996-97, a value which had fallen to 3,28 mGy six years later. In other European countries similar or slightly higher values have been described: for example, $3.9 \mathrm{mGy}$ in the United Kingdom (24) and 4.2 mGy in Germany (25). In studies carried out by Spanish universities, mean doses of 3.5 mGy have been recorded, although most installations used E sensitivity film (13), which was a rarity in our study, where only $0.83 \%$ of clinics in 203 used this type of film.

In Spain 92\% of radiological installations in 1996-7 used doses below $7 \mathrm{mGy}$ (considered as the reference dose to obtain a radiological image of an upper second molar until last year) $(14,26)$. This increased to $97.98 \%$ of installations by 2001 (26). The most recent EU recommendations lowered this reference dose to $4 \mathrm{mGy}$ (recommendation 5f), a level that $77.32 \%$ of Spanish dental clinics complied with in 2003 , when $75 \%$ of installations (third percentile) used doses lower than 4.8 mGy $(27,28)$.

\section{Conclusions}

Despite the gradual renewal of old radiological equipment during the years of the study, only $77.27 \%$ of installations inspected in 2003 complied with EU recommendations $(70 \mathrm{kVp}, 8 \mathrm{~mA}$ y $1.5 \mathrm{~mm}$ de $\mathrm{Al})$.

New legislation led to a substantial fall in the mean radiation dose applied during the study period, while the number of installations in which the equipment showed physical anomalies remained constant.

\section{References}

1. European Union. Council Directive 84/466 Euratom, laying down the basic measures for the radiation protection of persons undergoing medical examination or treatment. Official Journal of the European Communities No L 265, 5th October 1984:1-3.

2. European Union. Council Directive 96/29 Euratom, on health protection of sanitary persona and persons undergoing ionizing radiation. Official Journal of the European Communities No L 159, 29th June 1996. p. 1-114.

3. European Union. Council Directive 97/43 Euratom, on health protection of individuals against the dangers of ionizing radiation in relation to medical exposure, and repealing Directive 84/466 Euratom. Official Journal of the European Communities No L 180, 9th July 1997:22-7

4. BOE. Real Decreto 2071/1995, del Ministerio de Sanidad y 
Consumo por el que establecen los criterios de control de calidad en radiodiagnóstico.

5. BOE. Real Decreto 1976/1999, del Ministerio de Sanidad y Consumo, Reglamento sobre el establecimiento de los criterios de calidad en radiodiagnóstico. En: Boletín Oficial del Estado, 29 de Enero 1999:45891-900.

6. European Commission. European Guidelines on radiation protection in dental radiology. The safe use of radiographs in dental practices. Radiation Protection 136, 2004.

7. Vaño E, Tobarra B, Bezares M. Los datos de las exposiciones médicas en España para el informe UNSCEAR 2000. Revista de Física Médica. 2000;1:51-60.

8. Vaño E. Las exposiciones médicas en UNSCEAR 2000 y los datos del Comité Español. Radioprotección. 2001;30:14-9.

9. Horner K. Review article: radiation protection in dental radiology. Br J Radiol. 1994;67:1041-9.

10. Brown JE. Advances in dental imaging. Prim Dent Care. 2001;8:5962.

11. Horner K, Hirschmann PN. Dose reduction in dental radiography. J Dent. 1990;18:171-84.

12. Alcaraz M, Martínez-Beneyto Y, Velasco E. Control de calidad en instalaciones de radiodiagnóstico dental. Revista Europea de Odontoestomatología. 1999;11:265-74.

13. Van der Stelt PF. Radiation protection and quality assurance in dental radiography. A treatise from the European Community. Rev Belge Med Dent. 1996;51:111-22.

14. Alcaraz M, Martínez-Beneyto Y, Velasco E. Control de calidad en instalaciones de radiodiagnóstico dental. I Jornadas Universitarias de Protección Radiológica en Radiodiagnóstico. Málaga: Libro de resúmenes; 1999. p. 54.

15. González L, Vañó E, Fernández R. Reference doses in dental radiodiagnostic facilities. Br J Radiol. 2001;74:153-6.

16. Alcaraz M, Martínez-Beneyto Y, Perez L, Jodar S, Velasco E, Canteras M. The status of Spain's dental practices following the European Union directive concerning radiological installations. Oral Surg Oral Med Oral Pathol Oral Radiol Endod. 2004;98:476-82.

17. Martínez-Beneyto Y, Alcaraz M, Velasco E. La radiología dental intraoral en la práctica privada. XXI Congreso Nacional y VIII Internacional de la SEOEPYC, Murcia;1999. p. 18.

18. Alcaraz M, Jódar-Porlán S, Martínez-Beneyto Y, Velasco E, ChivaGarcía F. La radiología panorámica en el radiodiagnóstico dental. Revista Europea de Odontoestomatología. 2000;12:263-70.

19. Alcaraz M. Bases físicas y biológicas del radiodiagnóstico médico. Murcia: Universidad de Murcia, 2001.

20. Martínez-Beneyto Y, Alcaraz M, Perez 1, Jodar S, Velasco E. Modificación en la actuación radiológica dental: valoración tras cuatro años de estudio. Archivos de Odontoestomatología. 2003;19:296-307. 21. Hintze H. Radiographic screening examination: frequency, equipment, and film in general dental practice in Denmark. Scand J Dent Res. 1993;101:52-6.

22. Nakfoor CA, Brooks SL. Compliance of Michigan dentists with radiographic safety recommendations. Oral Surg Oral Med Oral Pathol. 1992;73:510-3.

23. Tuchyna T, Wilkinson S, Jacob CS. Compliance testing of medical diagnostic x-ray equipment: three years' experience at a major teaching hospital in Western Australia. Australas Phys Eng Sci Med. 2002;25:22-30

24. Zhang G, Yasuhiko O, Hidegiko Y. Absorbed doses to critical organs from full mouth dental radiography. Zhonghua Kou Qiang Yi Xue Za Zhi. 1999;34:5-8.

25. Napier ID. Reference doses for dental radiography. Br Dent J. 1999;186:392-6.

26. Cohnen M, Kemper J, Möbes O, Pawelzik J, Mödder U. Radiation dose in dental radiology. Eur Radiol. 2002;12:634-7.

27. Martínez-Beneyto Y, Alcaraz M, Perez L, Jodar-Porlán S, SauraIniesta A.M. Radiation protection and quality assurance in dental radiology in Spain: I. Intraoral Radiography. In: International Atomic Energy Agency, editors. International Conference of Radiological protection of patients in diagnostic and interventional radiology, nuclear medicine and radiotherapy. Vienna; 2001. p. 110-3.
28. Alcaraz M, Parra C, Martínez Beneyto Y, Velasco E, Canteras M. Is it true that the radiation dose to which patients are exposed has decreased with modern radiographic films?. Dentomaxillofac Radiol. 2009;38:92-7.

29. Alcaraz M, Navarro C, Vicente V, Canteras M. Dose reduction of intra-oral dental radiography in Spain. Dentomaxillofacial Radiology (en prensa).

\section{ACKNOWLEDGEMENTS}

This study was made possible with the help of the $\mathrm{R}+\mathrm{D}$ programme of the Spanish Nuclear Safety Council (BOE n ${ }^{\circ} 106,05 / 03 / 2007$;Res.,CSN 24/09/2007) 